\title{
Laparoscopic Adrenalectomy: Assessment of the Surgical Outcomes and Learning Curve for Large Adrenal Tumours
}

\author{
(1) Mehmet Necmettin Mercimek', • Murat Gülşen², • Ender Özden² \\ 1 Samsun Liv Hospital, Clinic of Urology, Samsun, Turkey \\ 2 Ondokuz Mayıs University Faculty of Medicine, Department of Urology, Samsun, Turkey
}

\begin{abstract}
Objective: Laparoscopic adrenalectomy (LA) is the treatment of choice for benign tumours of less than $6 \mathrm{~cm}$. However, there is still an ongoing debate regarding the exact cut-off value of the tumour size. The aim of this study was to determine the effect of tumour size on intraoperative and postoperative outcomes in patients undergoing $L A$ and also to estimate the learning curve for large adrenal tumours.

Materials and Methods: The data of 102 patients who underwent LA from April 2010 to October 2018 was retrospectively analysed. The patients were allocated to 2 groups according to tumour size: $<6 \mathrm{~cm}$ (group $1=76$ ) and $\geq 6 \mathrm{~cm}$ (group $2=26$ ). Both groups were compared in terms of age, gender, body mass index, tumour characteristics, operative data and complication rates. The patients were also allocated to four groups $(A, B, C$ and $D)$ according to the chronological order of their surgery in order to evaluate the learning curve.

Results: The mean age, gender, tumour laterality and BMI were similar in both groups. Tumour size ( $32.7 \mathrm{vs} 79.5 \mathrm{~mm}$, $\mathrm{p}=0.001)$, operation time $(53.3$ vs 72.6 minute, $p=0.001$ ), blood loss ( 65.8 vs $86.35 \mathrm{~mL}, \mathrm{p}=0.042$ ) were significantly different between groups 1 and 2 , respectively. Intraoperative and postoperative complication rates were also found to be significantly higher in group 2 . The first 25 cases were sufficient to complete the initial learning curve. It showed that surgical experience increased and operation time and blood loss decreased as the mean tumour size that is managed by LA increases.

Conclusion: LA is a reliable approach for the management of large adrenal tumours. However, we can conclude that the most important factor determining the safety and efficacy of LA is the surgical experience.
\end{abstract}

Keywords: Adrenalectomy, adrenal tumour, laparoscopy, learning curve

\section{Introduction}

The first laparoscopic adrenalectomy (LA) was described by Gagner et al. (1). Since then, many retrospective studies have reported that LA is beneficial for reducing estimated blood loss (EBL), postoperative pain, hospital stay and morbidity compared to open adrenalectomy (OA). Moreover, earlier return to normal activity and improved cosmetic outcomes have been reported as other significant advantages of laparoscopic surgery $(2,3,4)$. Over time, a variety of minimally invasive methods such as transperitoneal, retroperitoneal and robot-assisted approaches have been described for the management of adrenal masses alongside the advances in technology and surgical experience. LA is considered as the gold standard treatment modality for the management of various adrenal tumours. The conventional laparoscopic surgery has a difficult learning curve, whereas robotic surgery allows surgeons to perform surgeries in an environment where there is greater mobility in the presence of 3D imaging. However, it is stated that robot-assisted adrenalectomy has similar outcomes with LA and that tumour size is the most important limiting factor for laparoscopic retroperitoneal adrenalectomy (LRA) (5).

Despite all these innovations, the indications of laparoscopic surgery for adrenal masses larger than $6 \mathrm{~cm}$ are still controversial. Technical difficulties regarding the laparoscopic removal of large tumours and increased likelihood of malignancy with increasing tumour mass are the two main reasons for the controversy (6). While discussions on the tumour size continued, the efficacy and safety of laparoscopic surgery for tumours $\geq 8 \mathrm{~cm}$ was reported. There is not yet an exact cut-off value for tumour size that can be treated by $\operatorname{LA}(7,8)$. Moreover, a recent study also stated that

Cite this article as: Mercimek MN, Gülşen M, Özden E. Laparoscopic Adrenalectomy: Assessment of the Surgical Outcomes and Learning Curve for Large Adrenal Tumours. Bull Urooncol 2020;19(3):112-117

Address for Correspondence: Mehmet Necmettin Mercimek, Samsun Liv Hospital, Clinic of Urology, Samsun, Turkey Phone: +90 5435343964 E-mail: m.n.mercimek@hotmail.com ORCID-ID: orcid.org/0000-0002-0680-4451 
the number of cases requiring master level experience for LA was greater than 85 cases (9).

This study aimed to evaluate the effect of adrenal tumour size on intraoperative and postoperative outcomes. In addition, we investigated the learning curve by separating the patients into four groups (A, B, C and D) according to chronological order.

\section{Materials and Methods}

All the procedures performed in this study involving human participants were in accordance with the ethical standards of the institutional and/or national research committee (Ondokuz Mayıs University Clinical Research Ethics Committee - approval number: 2019/78, date: 14.03.2019) and the 1964 Helsinki declaration and its later amendments or comparable ethical standards. The study was registered in the Clinical Trials Register (www. clinicaltrials.gov, identifier NCT03830593) and informed consent was obtained from all the participants included in the study.

Demographic, intraoperative and postoperative data of 107 patients who underwent LA from April 2010 to October 2018 were analysed, retrospectively. The inclusion criteria were as follows: all hormonally active adrenal lesions, detection of increases in size of $<4 \mathrm{~cm}$ of adrenal tumours on serial imaging, solitary adrenal metastases without evidence of local invasion, tumours size $\geq 4 \mathrm{~cm}$, patients between the age of 18 and 80 and American Society of Anaesthesiologists score $\leq 3$. The patients having adrenal masses with specific suspicious signs of malignancy on imaging such as local invasion and irregular tumour margins were evaluated as ineligible for LA, excluded from this study and addressed to open surgery. Retroperitoneoscopic and laparoscopic partial adrenalectomies were also excluded from the study.

Totally 102 patients were included in the study. The patients were divided into 2 groups according to adrenal tumour size as $<6 \mathrm{~cm}$ (group 1, $\mathrm{n}=76$ ) and $\geq 6 \mathrm{~cm}$ (group 2, $\mathrm{n}=26$ ). Variables such as demographics, tumour size and laterality, operation time, $E B L$, per-operative and postoperative complications, length of hospital stay and final pathology result were compared between the two groups. In order to evaluate the learning curve, the patients were also classified into 4 consecutive groups including group A (1-25), group B (26-50), group C (51-75) and group D (76-102) according to the chronological order of their surgery. Variables including operation time, tumour size, EBL, hospital stay, and overall complications were used to investigate the learning curve.

The clinical diagnosis was made on the basis of a detailed history, physical examination, laboratory tests and imaging methods such as computed tomography and/or magnetic resonance imaging. The size of the tumour was defined using the largest size of the adrenal mass on imaging. Detailed hormonal and endocrinological evaluations were performed in terms of pheochromocytoma, hypercortisolism (Cushing's syndrome) and hyperaldosteronism (Conn's syndrome) in all the patients who were scheduled for definitive treatment.

According to the results of the hormonal evaluation, specific preoperative treatment was given to patients with a functional mass, and hormonal replacement therapy was also applied with respect to the postoperative hormonal status of the patients, when it is necessary. Laparoscopic transperitoneal adrenalectomies (LTAs) were performed at a tertiary care centre by a board certified and experienced laparoscopic surgeon. All demographic, intraoperative and postoperative variables were recorded. Postoperative complications were also evaluated using the Clavien-Dindo classification system (10).

\section{Surgical Technique}

All the surgical interventions were performed using a standard lateral transperitoneal approach. After general anaesthesia induction, a urinary drainage catheter and nasogastric tube were placed for decompression of the bladder and stomach respectively during insufflation, respectively. Patients were positioned at 90 degrees, slightly rotated toward the supine and flank-up positon, with the operative side facing upwards. The table is flexed to open the angle between the costal margin and the iliac crest. After a pneumoperitoneum was established using a Veress needle, a $10 \mathrm{~mm}$ optic trocar was placed below the costal margin at the lateral edge of the rectus muscle. On the left side, 2 additional working trocars, $(10 \mathrm{~mm}$ for the dominant hand and $5 \mathrm{~mm}$ for other) were placed and the $4^{\text {th }}$ additional trocar was used for liver retraction on the right side.

Dissection was maintained using monopolar hook cautery or Thunderbeat (Olympus, Tokyo, Japan). For right LTA, the first step was the dissection of the right triangular ligament of the liver, thereby mobilising it off of adrenal gland. Then, the retroperitoneal region was opened along the vena cava and the adrenal vein was identified. The adrenal gland was mobilised from the surrounding tissues after controlling the adrenal vein. For left LTA, the lateral peritoneal attachment of the colon was incised and then, the lateral and retroperitoneal attachments of the spleen were divided and the spleen and tail of the pancreas were dissected from the adrenal field. After opening the Gerota's fascia, the left adrenal vein and the rest of the gland were dissected off. Resected tissue was placed in an endo-bag, and removed using the modified Gibson's incision.

\section{Statistical Analysis}

The data were analysed using Statistics Package for Social Sciences version 24 (IBM SPSS ${ }$, Armonk, NY). In the comparison of the binary groups, independent sample $t$ (when normal distribution was provided), Mann-Whitney $U$ test (when it did not provide normal distribution) and the chi-square test were used to examine categorical data. The analysis results were presented as the mean \pm standard deviation for quantitative data and as frequency (percentage) for qualitative data. The significance level was set at $p<0.05$. For evaluation of the learning curve, One-Way ANOVA test was used to compare the numeric variables among groups $A, B, C$ and $D$. When the homogeneity of variances test was performed, it detected a $p>0.05$ (the normal distribution) for variables such as operation time, hospitalisation, EBL and tumour size. Then, Bonferroni test was used as Post-hoc tests and $\mathrm{p}<0.05$ was considered significant.

\section{Results}

There were 76 patients ( 23 males, 53 females) in group 1 and 26 patients ( 14 males, 12 females) in group 2 . The mean age 
was $49.7 \pm 12.2$ and $49.1 \pm 12.0(p=0.826)$ years old in groups 1 and 2, respectively. The mean tumour size was $32.7 \pm 12.7 \mathrm{~mm}$ (range, 10-56 mm) in group 1 and $79.5 \pm 21.9 \mathrm{~mm}$ (range, 60$170 \mathrm{~mm})$ in group $2,(\mathrm{p}=0.001)$. The mean operation time was $53.3 \pm 20.4$ minute in group 1 and $72.6 \pm 29.0$ minute in group 2 , $(p=0.001)$. The mean $E B L$ was significantly lower in group 1 $(65.8 \pm 28.6 \mathrm{~mL}$; range: $20-150 \mathrm{~mL})$ than in group $2(86.35 \pm 72.2$ $\mathrm{mL}$; range: $30-400 \mathrm{~mL}), \mathrm{p}=0.04$. Demographic, preoperative and operative data of both groups are shown in Table 1.

All the patients were managed using the LTA approach and conversion to an open surgery was not required in any cases in both groups. In the perioperative period, there were no spleen, colon or liver injuries in both groups. However, in the intraoperative period, a total of $3(11.5 \%)$ complications occurred in three distinct patients in group 2. One patient had a left renal vein and another had a right renal vein injury. In the patient with left renal vein injury, there was a $7 \mathrm{~cm}$ mass adjacent to the left renal vein and the pathology appeared as a paraganglioma. Moreover, in the patient with a right renal vein injury, there was an $8 \mathrm{~cm}$ mass that was reported as a myelolipoma. Both intraoperatively injured vessels were repaired laparoscopically suing the intracorporeal suture technique. The third patient had a diaphragmatic injury with opening of the pleural space on the left side, which was repaired laparoscopically without the need for conversion to open surgery.

\begin{tabular}{|c|c|c|c|}
\hline Variable* $^{*}$ & $\begin{array}{l}\text { Group } 1 \\
(n=76)\end{array}$ & $\begin{array}{l}\text { Group } 2 \\
(n=26)\end{array}$ & p \\
\hline \multicolumn{4}{|l|}{ Gender, n (\%) } \\
\hline Male/Female & $23 / 53$ & $14 / 12$ & 0.03 \\
\hline Mean age (years) & $49.7 \pm 12.2$ & $49.1 \pm 12.0$ & 0.826 \\
\hline Functioning tumours, n (\%) & $57(75)$ & $11(42.3)$ & 0.02 \\
\hline PCC & $28(36.8)$ & $9(34.6)$ & \multirow{3}{*}{0.03} \\
\hline Conn's disease & $9(13.1)$ & 0 & \\
\hline Cushing & $20(26.3)$ & $2(7.7)$ & \\
\hline Non-functioning tumours, n (\%) & $19(25)$ & $15(46.1)$ & \\
\hline \multicolumn{4}{|l|}{ ASA score, $n$} \\
\hline 1 & 35 & 8 & \multirow{3}{*}{0.347} \\
\hline 2 & 38 & 16 & \\
\hline 3 & 3 & 2 & \\
\hline $\mathrm{BMI}, \mathrm{kg} / \mathrm{m}^{2}$ & $29.4 \pm 5.5$ & $27.2 \pm 4.7$ & 0.07 \\
\hline \multicolumn{4}{|l|}{ Tumour localisation, $\mathbf{n}$} \\
\hline Right side & 40 & 10 & \multirow{2}{*}{0.212} \\
\hline Left side & 36 & 16 & \\
\hline Tumour size, mm & $32.7 \pm 12.7$ & $79.5 \pm 21.9$ & 0.001 \\
\hline Operation time, min & $53.3 \pm 20.4$ & $72.6 \pm 29.0$ & 0.001 \\
\hline Blood loss, mL & $65.86 \pm 28.6$ & $86.35 \pm 72.2$ & 0.042 \\
\hline Follow-up, month & $38.7 \pm 23.9$ & $26.3 \pm 27.14$ & 0.03 \\
\hline Hospital stay, day & $1.22 \pm 0.6$ & $2.12 \pm 2.2$ & 0.003 \\
\hline \multicolumn{4}{|c|}{$\begin{array}{l}\text { ASA: American society of anaesthesiologists, BMI: Body mass index, } \mathrm{mm} \text { : } \\
\text { Millimeter, min: Minute, PCC: Pheochromocytoma, SD: Standard deviation, } \\
\text { statistically significant difference was }(p<0.05) \text {, *: Variables are presented as } \\
\text { mean } \pm \text { SD or number (percent) }\end{array}$} \\
\hline
\end{tabular}

Regarding postoperative complications, it was determined that the complication rate was higher in group $2(\mathrm{p}=0.01)$. Overall, 4 (15.3\%) patients had complications in the postoperative period in the group 2. One patient required transfusion due to reduced haemoglobin (grade 2), one patient had a chylous drainage lasting 3 days (grade 1), one patient had postoperative fever (grade 1) and the other one had a fat necrosis on the incision line (grade 2). In group 1, postoperative complications were detected in 2 (2.6\%) patients. No patient needed a postoperative transfusion. Postoperative Reversible Encephalopathy syndrome developed in a patient that lasted for 3 days and improved with medical treatment (grade 2), while the other patient had a fat necrosis on the incision line (grade 2). Complications are shown in Table 2.

Pathological evaluation showed that 72 (94.7\%) patients were benign and $4(5.3 \%)$ were malignant in group 1, while 19 $(73.1 \%)$ patients were benign and 7 (26.9\%) were malignant in group 2. The final pathology results are shown in Table 3. Upon evaluation of the final pathology results in terms of positive surgical margin in patients who had a malignant disease, no positive surgical margin was detected in both groups. Moreover, in group 2, only 3 patients were shown to have primary adrenocortical carcinoma (ACC) on the final pathological examination and they were followed-up for 35, 26 and 18 months, respectively. Local and distant recurrences or metastasis were not detected during the follow-up.

When the results of the groups (A, B, C and D) allocated by chronological order for the definition of the learning curve were evaluated, there was a statistically significant decrease in the operation time, increase in the tumour size as well as a decrease in the EBL after the completion of the learning curve. However, there was no statistically significant difference in the length of hospital stay and overall complications between the groups. The details of the learning curve are shown in Table 4.

\section{Discussion}

LA is the gold standard method for the surgical management of benign adrenal masses $<6 \mathrm{~cm}$ in size (11). Laparoscopic

\begin{tabular}{|c|c|c|}
\hline & $\begin{array}{l}\text { Group } 1 \\
(n=76)\end{array}$ & $\begin{array}{l}\text { Group } 2 \\
(n=26)\end{array}$ \\
\hline \multicolumn{3}{|l|}{ Intraoperative complications } \\
\hline Renal vein injury & - & 2 \\
\hline Diaphragmatic injury & - & 1 \\
\hline Total \% & 0 & $11.5 \% p=0.01$ \\
\hline \multicolumn{3}{|l|}{ Postoperative complications* } \\
\hline Blood transfusion (grade 2) & - & 1 \\
\hline PRES (grade 2) & 1 & - \\
\hline Chylous drainage (grade 1) & - & 1 \\
\hline Fever (grade 1) & - & 1 \\
\hline Fat necrosis (grade 2) & 1 & 1 \\
\hline Total \% & $2.6 \%$ & $15.3 \% p=0.01$ \\
\hline
\end{tabular}


surgery has significant advantages including the decrease in postoperative pain and analgesic requirement, earlier resumption of oral intake, shorter hospital stay, earlier return to normal life and better cosmetic outcomes compared with OA (12). Despite the innovations in minimally invasive treatment methods such as laparoscopic, robot-assisted, and single-incision procedures, the widely accepted view is that OA is recommended for patients who have a clinical suspicion of ACC. It was reported that the incidence of ACC for tumour sizes $<4 \mathrm{~cm}, 4-6 \mathrm{~cm}$ and $>6 \mathrm{~cm}$ is $2 \%, 6 \%$ and $25 \%$, respectively. However, tumour size alone is not a decision-making criterion for malignancy. It has been shown that $13.5 \%$ of adrenal masses smaller than $5 \mathrm{~cm}$ might reveal an ACC (13). In addition, large necrosis areas, irregular borders and the presence of local invasion on radiological evaluation may suggest malignancy $(14,15)$. It has been strongly emphasised that complete resection of ACCs with a negative surgical margin is the strongest predictor of mortality and it has been suggested the necessary care should be taken in selecting patients (16).

\begin{tabular}{|c|c|c|c|c|}
\hline & \multicolumn{2}{|c|}{ Group $1(n=76)$} & \multicolumn{2}{|c|}{ Group $2(n=26)$} \\
\hline & $\begin{array}{l}\text { Frequency } \\
\text { (n) }\end{array}$ & $\begin{array}{l}\text { Percent } \\
(\%)\end{array}$ & $\begin{array}{l}\text { Frequency } \\
\text { (n) }\end{array}$ & $\begin{array}{l}\text { Percent } \\
(\%)\end{array}$ \\
\hline Adenoma & 50 & 65.7 & 2 & 7.7 \\
\hline PCC & 14 & 18.4 & 9 & 34.6 \\
\hline ACC & - & - & 3 & 11.5 \\
\hline Solid metastasis & 3 & 3.9 & 3 & 11.5 \\
\hline Mesenchymal tumour & 1 & 1.3 & - & - \\
\hline Lymphoma & - & - & 1 & 3.8 \\
\hline Other benign lesions* & 8 & 10.5 & 8 & 30.7 \\
\hline Total & 76 & 100 & 26 & 100 \\
\hline \multicolumn{5}{|c|}{ Overall final pathology $p<0.05$} \\
\hline Benign & 72 & & 19 & \\
\hline Malign & 4 & & 7 & \\
\hline \multicolumn{5}{|c|}{$\begin{array}{l}\text { ACC: Adrenocortical carcinoma, PCC: Pheochromocytoma, *: Cyst, ganglioneuroma, } \\
\text { schwannoma, myelolipoma, solid metastasis: renal cell carcinoma, colon cancer, } \\
\text { breast cancer and lung cancer metastasis }\end{array}$} \\
\hline
\end{tabular}

In this study, ACC was detected in 3 (11.5\%) of 26 patients in group 2. In all of these patients, the masses were completely removed without damaging the tumour capsule. Also, it is shown in the final pathology report that we obtained a negative surgical margin. No recurrence was detected on follow-up in patients with ACC. Furthermore, no ACC was detected in any patient in group 1 according to the final pathology reports.

Debates on this topic such as operation indications and limitations, advantages and disadvantages of the recent approaches and comparison of safety and effectiveness of minimally invasive techniques are still ongoing. Although many experienced surgeons have reported that laparoscopic treatment of adrenal masses of up to $12-15 \mathrm{~cm}$ is available, no generally accepted cut-off value in terms of tumour size has been described $(17,18,19)$. Consequently, we performed LA for all patients without a local invasion on radiological imaging and these patients did not require additional open surgery.

It has been reported that LRA decreases operation time, hospital stay and postoperative analgesic requirement compared with LA (20). Morbidity and mortality rates are have also been reported similarly in those techniques (21). However, the most important limiting factor for LRA is mass size. Wang et al. (22) reported that $>7 \mathrm{~cm}$ large masses leads to increased operative time and more blood loss. It has been shown that LRA and LA were similar in terms of perioperative and postoperative complications and conversion to an open surgery (23). Besides, Castillo et al. (24) reported that adrenal tumour that were larger than 8 $\mathrm{cm}$ increased the duration of surgery, blood loss and hospital stay, but did not affect perioperative morbidity. In the present study, it was determined that as the tumour size increased, the operation time and the length of hospital stay also increased. Additionally, EBL was found to be higher in group 2 when the 2 groups were compared $(p=0.042)$. Technically, a transperitoneal lateral laparoscopic approach has been implemented to all of our patients with adrenal tumours who were included in this study. This is because we believe that this technique will allow the surgeon to create a more comfortable working space and will also enable the laparoscopic repair of vascular injuries without the need to convert to an open surgery.

Table 4. The learning curve for laparoscopic adrenalectomy

\begin{tabular}{|c|c|c|c|c|c|}
\hline Variables* & Group A (1-25) & Group B (26-50) & Group C (51-75) & Group D (76-102) & $p$ \\
\hline Operation time (min) & $71.52 \pm 27.0$ & $56.4 \pm 17.7$ & $54.8 \pm 25.8$ & $50.96 \pm 21.79$ & 0.01 \\
\hline Tumour size (mm) & $35.48 \pm 20.37$ & $41.8 \pm 22.28$ & $45.20 \pm 24.34$ & $55.22 \pm 31.21$ & 0.04 \\
\hline$<6 \mathrm{~cm}$ & $21(84)$ & $20(80)$ & $19(76)$ & $16(59.3)$ & \multirow{2}{*}{0.04} \\
\hline$\geq 6 \mathrm{~cm}$ & $4(16)$ & $5(20)$ & $6(24)$ & $11(40.7)$ & \\
\hline \multicolumn{6}{|l|}{ Overall complication } \\
\hline No & 23 & 24 & 24 & 23 & \multirow{3}{*}{0.629} \\
\hline Minor (grade I-II) $\alpha$ & 2 & 1 & 1 & 3 & \\
\hline Major (grade III-V) $\alpha$ & 0 & 0 & 0 & 1 & \\
\hline
\end{tabular}


A surgeon who performed $\geq 4$ adrenalectomies per year was defined as a high-volume surgeon by Lindeman et al. (25). We found that mortality and complications were inversely proportional to the number of annual cases of the surgeon. Moreover, low surgeon volume was found to be an independent indicator of complications. The most significant advantage of LA is that it has lower morbidity and mortality rates compared to the open technique. In the laparoscopic technique, the overall complication rates are stated as less than $10 \%$ and the rate of conversion to an open surgery was 3.5\%. Furthermore, laparoscopic surgery might need to be converted to an open surgery due to complications such as vascular or visceral injuries. In this study, the overall complication rate was $8.8 \%$ (9 of 102 patients). Intraoperative complications were more common in group 2 and were detected in 3 (11.5\%) patients; 2 of 3 had renal vein injury and the other had a diaphragm injury.

According to the literature, the first 30 cases were evaluated as part of the learning curve $(11,26)$. In the present study, in contrast to the previous literature, patients were divided into 4 distinct groups as A, B, C and D according to chronological order and then the learning curve was evaluated. In this study, 25 patients were included in the first 3 groups (A, B, C) and 27 patients in the last group (D). It was found that the reduction in the mean operating time, tumour size and blood loss was statistically significant $(p<0.05)$. However, hospital stay and overall complication rates were similar among the groups over time $(p>0.05)$. We can conclude that the completion of the learning curve requires approximately 25 cases, while laparoscopic treatment of large adrenal masses requires more than 75 cases of experience to achieve a significant decrease in the operation time and blood loss. Moreover, increased tumour size may pose a risk for intraoperative and postoperative complications.

The final pathology reports were evaluated between group 1 and group 2. As tumour size increases, ACC was likely to be detected, if solitary adrenal metastasis is excluded in patients with tumour size $>6 \mathrm{~cm}$. In the final pathological exam, only 2.94\% (3 of 102) of patients had revealed ACC. Furthermore, the ratio of functional and benign masses increases in cases with an adrenal mass size less than $6 \mathrm{~cm}$. It was reported that resection of isolated metachronous adrenal metastasis of many kinds of primary cancers with the laparoscopic technique may help to achieve a negative surgical margin and may improve the overall survival (27). As a general practice, our primary surgical principle is to identify surrounding tissues before the tumour is dissected. For this reason, adjacent structures including renal vein, the upper pole of the kidney and the vena cava or aorta are first identified and then tumour dissection is completed. Furthermore, specific attention to oncological principles during surgery resulted in achieving a negative surgical margin in all the patients whose final pathology results were revealed as malignancy in both groups.

\section{Study Limitations}

There are some limitations to the present study. The retrospective nature and the difference in the number of patients between groups are the main limitations. However, it may be difficult to design a prospective study in patients who underwent LA. On the other hand, all the surgeries were performed by a single surgeon and calculating the learning curve in terms of evaluation of the surgical experience over time in the entire cohort may reduce this limitation.

\section{Conclusion}

LA is a reliable and an effective approach for the management of large adrenal tumours $(>6 \mathrm{~cm})$. However, in order to improve surgical outcomes and reduce complications in patients with large adrenal tumours, it is necessary to have competent experience in LA.

\section{Acknowledgements}

Publication: The results of the study were not published in full or in part in form of abstracts.

Contribution: There is not any contributors who may not be listed as authors.

Conflict of Interest: No conflict of interest was declared by the authors.

Financial Disclosure: The authors declared that this study received no financial support.

\section{Ethics}

Ethics Committee Approval: All the procedures performed in this study involving human participants were in accordance with the ethical standards of the institutional and/or national research committee (Ondokuz Mayıs University Clinical Research Ethics Committee - approval number: 2019/78, date: 14.03.2019) and the 1964 Helsinki Declaration and its later amendments or comparable ethical standards.

Informed Consent: Informed consent was obtained from all the participants included in the study.

Peer-review: Externally peer-reviewed.

\section{Authorship Contributions}

Critical Review: E.Ö., Concept: M.N.M., M.G., E.Ö., Design: M.N.M., M.G., E.Ö., Data Collection or Processing: M.N.M., M.G., E.Ö., Analysis or Interpretation: M.N.M., M.G., E.Ö., Literature Search: M.N.M., M.G., Writing: M.N.M., M.G., E.Ö.

\section{References}

1. Gagner M, Lacroix A, Bolte E. Laparoscopic adrenalectomy in Cushing's syndrome and pheochromocytoma. N Engl J Med 1992;327:1033.

2. Hazzan D, Shiloni E, Golijanin D, et al. Laparoscopic vs open adrenalectomy for benign adrenal neoplasm. Surg Endosc 2001;15:1356-1358.

3. Wu CT, Chiang YJ, Chou CC, et al. Comparative study of laparoscopic and open adrenalectomy. Chang Gung Med J 2006;29:468-473.

4. Haveran LA, Novitsky YW, Czerniach DR, et al. Benefits of laparoscopic adrenalectomy: a 10-year single institution experience. Surg Laparosc Endosc Percutan Tech 2006;16:217-221.

5. Brandao LF, Autorino R, Laydner $\mathrm{H}$, et al. Robotic versus laparoscopic adrenalectomy: a systematic review and meta-analysis. Eur Urol 2014;65:1154-1161.

6. Chuan-Yu S, Yat-Faat H, Wei-Hong D, et al. Laparoscopic adrenalectomy for adrenal tumors. Int J Endocrinol 2014;2014:241854. 
7. Zografos GN, Farfaras A, Vasiliadis G, et al. Laparoscopic resection of large adrenal tumors. JSLS 2010;14:364-368.

8. Parnaby CN, Chong PS, Chisholm L, et al. The role of laparoscopic adrenalectomy for adrenal tumours of $6 \mathrm{~cm}$ or greater. Surg Endosc 2008;22:617-621.

9. Teksoz S, Kilboz BB, Bukey Y. Experience of an endocrine surgeon in laparoscopic transperitoneal adrenalectomy. BMC surgery 2019;19:134.

10. Clavien PA, Barkun J, de Oliveira ML, et al. The Clavien-Dindo classification of surgical complications: five-year experience. Ann Surg 2009;250:187-196.

11. Conzo G, Gambardella C, Candela G, et al. Single center experience with laparoscopic adrenalectomy on a large clinical series. BMC Surg 2018;19:2.

12. Bulus $\mathrm{H}$, Uslu HY, Karakoyun $\mathrm{R}$, et al. Comparison of laparoscopic and open adrenalectomy. Acta chirurgica Belgica 2013;113:203-207.

13. Barnett CC Jr, Varma DG, El-Naggar AK, et al. Limitations of size as a criterion in the evaluation of adrenal tumors. Surgery 2000;128:973-982.

14. Conzo G, Tartaglia E, Gambardella C, et al. Minimally invasive approach for adrenal lesions: Systematic review of laparoscopic versus retroperitoneoscopic adrenalectomy and assessment of risk factors for complications. Int J Surg 2016;(28 Suppl 1):118-123.

15. Sturgeon C, Shen WT, Clark OH, et al. Risk assessment in 457 adrenal cortical carcinomas: how much does tumor size predict the likelihood of malignancy? J Am Coll Surg 2006;202:423-430.

16. Huynh KT, Lee DY, Lau BJ, et al. Impact of Laparoscopic Adrenalectomy on Overall Survival in Patients with Nonmetastatic Adrenocortical Carcinoma. J Am Coll Surg 2016;223:485-492.

17. Mesci A, Celik O, Akand M, et al. Evaluation of laparoscopic transperitoneal adrenalectomy: is it feasible for large masses? Minerva Urol Nefrol 2015;67:175-178.
18. Maestroni U, Ziglioli F, Dinale F, et al. Is laparoscopy contraindicated in giant adrenal masses? Surg Laparosc Endosc Percutan Tech 2010;20:288-290.

19. Maestroni U, Ferretti S, Ziglioli F, et al. Laparoscopic adrenalectomy in giant masses. Urologia 2011;(Suppl 18):54-58.

20. Cabalag MS, Mann GB, Gorelik A, Miller JA. Comparison of outcomes after laparoscopic versus posterior retroperitoneoscopic adrenalectomy: a pilot study. Surg Laparosc Endosc Percutan Tech 2014;24:62-66.

21. Berber E, Tellioglu G, Harvey A, et al. Comparison of laparoscopic transabdominal lateral versus posterior retroperitoneal adrenalectomy. Surgery 2009; 146:621-625; discussion 625-626.

22. Wang B, Ma X, Li H, et al. Anatomic retroperitoneoscopic adrenalectomy for selected adrenal tumors $>5 \mathrm{~cm}$ : our technique and experience. Urology 2011;78:348-352.

23. Chai YJ, Kwon H, Yu HW, et al. Systematic Review of Surgical Approaches for Adrenal Tumors: Lateral Transperitoneal versus Posterior Retroperitoneal and Laparoscopic versus Robotic Adrenalectomy. Int J Endocrinol 2014;2014:918346.

24. Castillo OA, Rodriguez-Carlin A, Lopez-Vallejo J, Borgna V. Complications associated with laparoscopic adrenalectomy: Description and standardized assessment. Actas Urol Esp 2014;38:445-450.

25. Lindeman B, Hashimoto DA, Bababekov YJ, et al. Fifteen years of adrenalectomies: impact of specialty training and operative volume. Surgery 2018;163:150-156.

26. Erbil Y, Barbaros U, Karaman G, et al. The change in the principle of performing laparoscopic adrenalectomy from small to large masses. Int J Surg 2009;7:266-271.

27. Creamer J, Matthews BD. Laparoscopic adrenalectomy for cancer. Surg Oncol Clin N Am 2013;22:111-124. 